\title{
Response of white clover cultivars to sheep and beef cattle grazing management across three pastoral environments in New Zealand
}

\author{
Angus HESLOP ${ }^{1}$, Zulfi JAHUFER ${ }^{1,{ }^{*}}$, Greig COUSINS ${ }^{2}$, Derek WOODFIELD ${ }^{2}$, John FORD ${ }^{2}$ \\ ${ }^{1}$ AgResearch Ltd., Grasslands Research Centre, Private Bag 11008, Palmerston North, New Zealand. \\ ${ }^{2} P G G$ Wrightson Seeds Limited, Building 88, C/- Grasslands Research Centre, Private Bag 11008, \\ Palmerston North, New Zealand. \\ *Corresponding author: zulfi.jahufer@agresearch.co.nz
}

\begin{abstract}
White clover (Trifolium repens L.) is the main legume component in temperate perennial pasture swards in New Zealand. Developing broadly adapted cultivars is an important objective in white clover breeding programmes. Field trials across years, seasons, locations and grazing environments enable breeders to select superior material, and assess the merit of new cultivars available to farmers. Data from field trials evaluating 44 experimental synthetics and 16 cultivars for seasonal growth and leaf size across three locations in New Zealand (Kerikeri (cattle grazed), Palmerston North (cattle grazed) and Lincoln (sheep grazed)), were analysed to demonstrate the importance of conducting multi-location and year evaluation trials. Among the 16 cultivars, $c v$ Legacy showed above average performance across all three locations. The $c v$ Hilltop, when compared among similar leaf size material, showed above average seasonal growth across years under rotational sheep grazing management during the first 4 years of the trial at Lincoln. Hilltop showed above average seasonal growth under set stocking with sheep in years 5 and 6 at Lincoln.
\end{abstract}

Key words: Genotype, environment, grazing, adaptation, growth

\section{Introduction}

White clover (Trifolium repens L.) and perennial ryegrass (Lolium perenne) based pastures form the main feed for livestock industries in temperate grazing environments of New Zealand. White clover is a significant source of high-quality animal feed, and enhances soil fertility through symbiotic fixation of atmospheric nitrogen (Frame and Newbould 1986). Breeding programmes in New Zealand have a long history of successfully developing a range of small to large leaved white clover cultivars for local and overseas grazing environments (Brock et al., 1989; Hay and Lancashire 1996).

Many white clover cultivars are developed for broad adaptation across a range of target grazing environments. This is an important objective not only in white clover breeding, but for other forage and crop species (Ewing 2019). When developing cultivars with broad adaptation, breeders must assess the change in relative performance of breeding lines across environments, referred to as genotype-byenvironment $(\mathrm{G} \times \mathrm{E})$ interactions (Cooper and Byth 1996). This is conducted by using multi-year-location field trials which enable identification of location specific and broadly adapted entries. In comparison with crops grown as monocultures, a key source of $\mathrm{G} \times \mathrm{E}$ interactions in perennial forages, such as white clover, is the impact of animal grazing.

White clover cultivar development programmes have been challenged by significant $\mathrm{G} \times \mathrm{E}$ interactions (Jahufer et al., 2002). Multi-year and multi-location trials conducted across important grazing environments in New Zealand help breeders to select superior material and assess the merit of new commercial cultivars. The following study was a multi-year study across three locations in New Zealand (Kerikeri, Palmerston North and Lincoln). It evaluated 44 experimental varieties and 16 commercial cultivars for seasonal growth to summarise patterns of cultivar performance in relation to differences in location, year, and animal grazing management.

\section{Material and methods \\ Entries and trial locations}

A total of 60 white clover entries, including 16 cultivars and 44 experimental synthetics (progeny generated from a polycross among selected parents), were evaluated. Leaf sizes were categorised as very small (VS); small medium (SM); medium (M); medium large (ML); large (L) and very large (VL). The cultivars were: AberAce (VS), AberDance (M), Bounty (M), Apex (M), Demand (SM), Hilltop (S), Kakariki (VL), Klondike (L), Kopu II (L), Kotare (L), Legacy (L), Prestige (S), Reisling (ML), Sustain (ML), Tahora (VS) and Tribute (ML). In 2014, field trials were established at Northland (Plant and Food Research Station, Kerikeri (Ker): $35^{\circ} 13^{\prime}$ S, $\left.173^{\circ} 56^{\prime} \mathrm{E}\right)$, Palmerston North (PN; AgResearch, Aorangi Research station: $\left.40^{\circ} 19^{\prime} \mathrm{S}, 175^{\circ} 29^{\prime} \mathrm{E}\right)$ and Lincoln (Lin, AgResearch Research Centre: $43^{\circ} 38^{\prime} \mathrm{S}$, $\left.172^{\circ} 30^{\prime} \mathrm{E}\right)$. The soil types at each site were Okaihau gravely clay (Taylor and Pohlen 1968), Kairanga silt 
loam (Cowie 1978) and Wakanui silt loam soil (Hewitt 1993) at Ker, PN and Lin, respectively. The long-term average minimum/maximum ambient temperatures at each location; $11.8 / 19.7,8.5 / 17.8,7.3 / 17.2^{\circ} \mathrm{C}$, at Ker, PN, and Lin, respectively. The long-term average annual rainfall was: 1775,978 and $680 \mathrm{~mm}$, respectively for each site.

\section{Field trials}

In autumn 2014, at all three locations, perennial ryegrass cultivar Ceres One50 (AR37) was direct drilled into the experimental area at the rate of 20 $\mathrm{kg} / \mathrm{ha}$. This was followed immediately with hand sowing of the white clover entries at $5 \mathrm{~kg} / \mathrm{ha}$ in $1 \mathrm{~m}$ $\times 2 \mathrm{~m}$ plots using a row-column experimental design with three replicates. Post sowing, Preside ${ }^{\mathrm{TM}}$ (800 g/ $\mathrm{kg}$ flumetsulam at $65 \mathrm{~g} / \mathrm{ha}$ ) herbicide was applied to control broadleaf weeds in the establishing pasture. The herbicide Banvel ${ }^{\mathrm{R}}(200 \mathrm{~g} /$ litre dicamba at $250 \mathrm{ml} / 00$ litres) was used periodically to control broad leaved weeds and the emergence of adventive white clover from buried seed. Superphosphate fertiliser $(150 \mathrm{~kg} / \mathrm{ha})$ was applied across the trials in late autumn in years 1 and 3 , and $15-20 \mathrm{~kg} / \mathrm{ha}$ nitrogen was applied two or three times each year in the cattle grazed trials and a one-off maintenance dressing of $20 \mathrm{~kg} / \mathrm{ha}$ was applied in the Lincoln sheep grazed trial.

\section{Grazing}

Rotational grazing was implemented at all three locations, PN (beef cattle), Ker (beef cattle) and Lin (sheep), during the first 4 years. The trial at Lincoln was continued for an extra 2 years under set stocking management. Grazing at PN and Ker was conducted when the sward dry matter yield was estimated to be $2,500 \mathrm{~kg} / \mathrm{ha}$. Each location was grazed for a period of 2 to $3 \mathrm{~h}$ with cattle, season dependent. Under a rotational sheep grazing management at Lin, grazing commenced at an estimated sward dry matter yield of 2,000 to 2,200 kg/ha and mob-stocked for 24-48 h. At Lin, under set stocking grazing management during years 5 and 6 , the trial was grazed for a period of 6 to 8 weeks, season dependent. The sheep were removed at approximately $1000 \mathrm{~kg} /$ ha residual dry matter yield for the set stocked management and between 1100 and 1200 $\mathrm{kg} / \mathrm{ha}$ for rotational managed pastures.

Two to three weeks post grazing, yield assessment scores were conducted. The growth of white clover was visually scored at each location prior to grazing, using a scale that ranged from 1 (poor) to 9 (high), based on Ford et al. (2015). Leaf size was measured before grazing using a scale of 1 (very small) to 5 (very large) after Ford et al. (2015).

\section{Data analysis}

Seasonal growth and leaf score data were analysed using variance component analysis based on the Residual Maximum Likelihood (REML) (Patterson and Thompson 1971; Patterson and Thompson 1975: Harville 1977) procedure in DeltaGen (Jahufer and Luo 2018). The estimated entry means were based on Best Linear Unbiased Predictors (BLUP's) according to White and Hodge (1989). The growth score data were analysed as a) on an individual location basis across 4 years, and across all years, seasons and locations, $b$ ) within each season across all 4 years and locations, c) within years 1,2,3 and 4 under rotational grazing management, and years 5 and 6 under set stocking, at Lin only. Leaf size score data were analysed across all seasons, over 3 years and from the three locations. In order to assess the effect of the two grazing managements at Lin, specific analysis of leaf size data collected under rotational grazing and post set stocking were conducted. Pattern analysis, a combination of cluster analysis and principal component analysis, was conducted using DeltaGen (Jahufer and Luo 2018). The purpose of this analysis was to graphically summarize the performance of the 16 cultivars across the three locations, based on seasonal growth.

\section{Results and Discussion}

\section{Across-location analyses}

Analysis of variance indicated significant $(\mathrm{P}<0.05)$ genotypic variation among the 60 white clover entries for mean leaf size across 4 years and three locations (Table 1). There was significant $(\mathrm{P}<0.05)$ variation among entries for leaf size within each sheep grazing management, rotational and set stocking group at Lin. A significant $(\mathrm{P}<0.05)$ genotype-by-location interaction for leaf size indicated a relative change among the entries for expression of this trait across locations. A key driver for this could be attributed to differences in grazing management, with beef cattle at Ker and PN and sheep at Lin. Abberton and Marshall (2010) indicated that small leaf cultivars were more suitable for sheep grazing, medium leaf clovers for rotational grazing and large leaf types for cattle grazing. Leaf morphology changes in white clover have been attributed to a certain degree of phenotypic plasticity (Caradus 1994). The effect of rotational and set stock grazing management on white clover leaf size has previously been demonstrated by Brock and Hay (1996).

There were differences in the rankings of cultivar mean leaf size scores depending on whether plants were rotationally grazed or set stocked with sheep at Lin (Figure 1). The cultivars Legacy, Kakariki, Kopu II, Prestige and AberAce showed a significant reduction in leaf size under set stocked sheep grazing compared with rotational grazing. This was in agreement with Brock and Hay (1996) who reported that the leaf area of cultivars Tahora, Huia, Pitau and Kopu, were reduced 


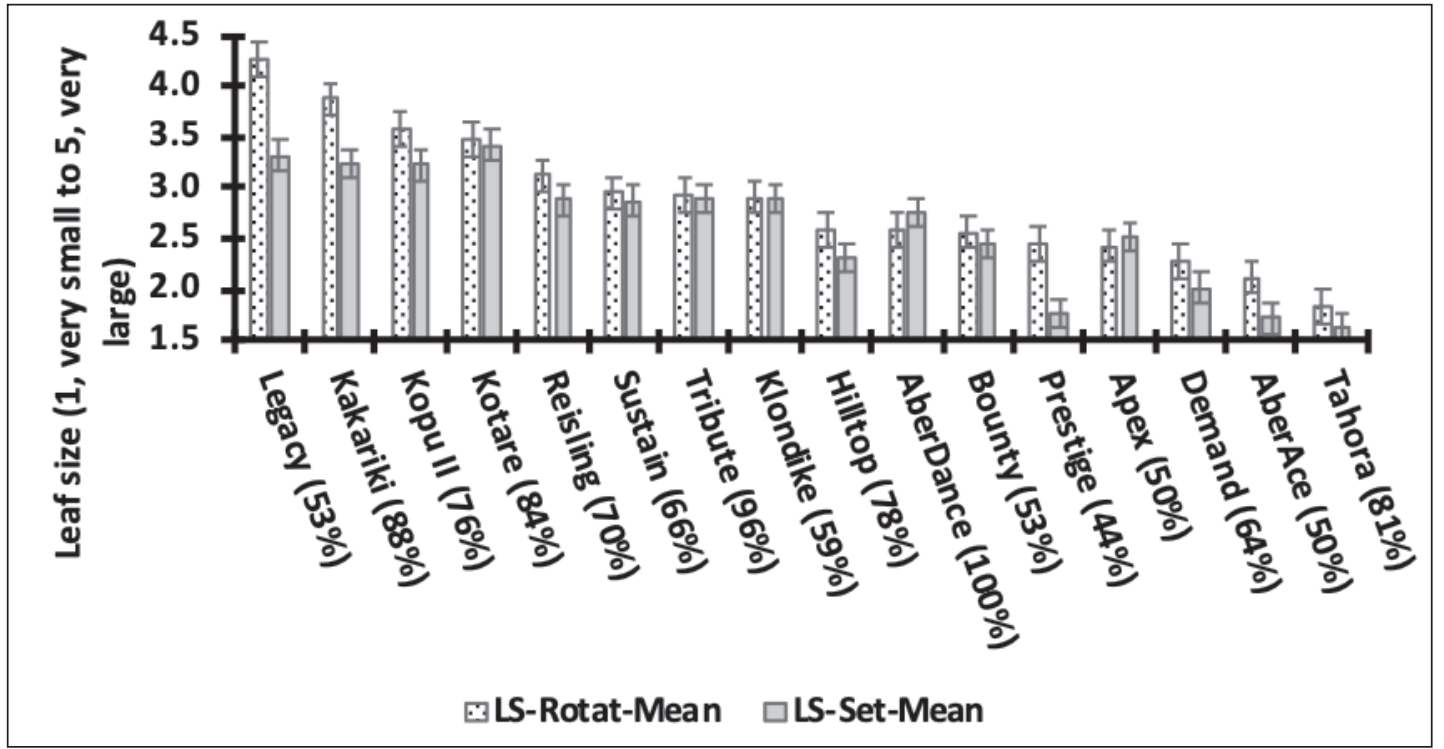

Figure 1 White clover leaf sizes of the 16 cultivars ordered by mean scores across 4 years of rotational sheep grazing (years 1 to 4), compared with 2 years of set stock sheep grazing (years 5 and 6 ), at Lincoln. The \%HCN measured for each cultivar at the beginning of the trial is indicated within brackets.

under set stocking with sheep in comparison rotational grazing.

Genotypic variation among the 60 white clover entries for mean seasonal growth across 4 years under rotational grazing at each of the individual locations, $\mathrm{PN}, \mathrm{Ker}$ and Lin, was significant $(\mathrm{P}<0.05)($ Table 2$)$. At each location, there was a significant $(\mathrm{P}<0.05)$ genotype-by-year interaction. Significant $(\mathrm{P}<0.05)$ genotype-by-season interactions were estimated at PN and Lin. Analysis of Spring, Summer, Autumn and Winter growth across 4 years and the three locations indicated significant $(\mathrm{P}<0.05)$ genotypic variation within each season, among the 60 entries (Table 2). There was a significant $(\mathrm{P}<0.05)$ genotype-by-location interaction within each season for growth, which indicated seasonal changes in the relative performance among the 60 entries across locations.

Analysis of seasonal growth data collected across the 4 years and three locations showed significant $(\mathrm{P}<0.05)$ genotypic variation among the entries for broad adaptation. Significant $(\mathrm{P}<0.05)$ line-by-year interactions for the proportion of clover in sward, clover dry weight, clover leaf number per unit area and leaf size was reported from other experiments, where 32 white clover cultivars and elite breeding lines were evaluated in mixed species plots that were rotationally grazed by sheep and cattle over a period of three years (Caradus 1991; 1993). Jahufer et al. (2016) reported

Table 1 Estimated variance components ${ }^{\dagger}$ and associated standard error $( \pm$ SE) for leaf size among the 60 white clover entries $(44$ experimental synthetics and 16 commercial cultivars) evaluated at Kerikeri, Palmerston North and Lincoln, from Residual Maximum Likelihood analysis.

\begin{tabular}{|c|c|c|c|c|c|}
\hline Traits & $\sigma_{g}^{2}$ & $\sigma_{\text {gy }}^{2}$ & $\sigma_{\text {gs }}^{2}$ & $\sigma_{g l}^{2}$ & $\sigma_{\varepsilon}^{2}$ \\
\hline $\begin{array}{l}\text { Mean leaf size across seasons, } \\
4 \text { years and } 3 \text { locations }\end{array}$ & $0.123^{\dagger} \pm 0.035$ & $\mathrm{~ns}^{*}$ & ns & $0.106 \pm 0.032$ & $0.428 \pm 0.029$ \\
\hline $\begin{array}{l}\text { Mean leaf size across } 4 \text { years at Lincoln: } \\
\text { Rotational grazing }\end{array}$ & $0.354 \pm 0.075$ & Ns & ns & - & $0.314 \pm 0.032$ \\
\hline $\begin{array}{l}\text { Mean leaf size across years } 5 \text { and } 6 \text { at Lincoln: } \\
\text { Set stocking }\end{array}$ & $0.309 \pm 0.065$ & $0.057 \pm 0.024$ & ns & - & $0.399 \pm 0.023$ \\
\hline
\end{tabular}

* non-significant $(\mathrm{P}>0.05)$,

† a variance component was considered significant $(\mathrm{P}<0.05)$ at 1.96 (form two-tailed test) times greater than its standard error. Only significant $(\mathrm{P}<0.05)$ variance components are reported. Variance components: $\sigma_{g}^{2}$, genotypic; $\sigma_{g y}^{2}$ genotype-by-year interaction; $\sigma_{g s}^{2}$, genotype-by-season interaction; $\sigma_{g /}^{2}$ genotype-by-location interaction; $\sigma_{\varepsilon}^{2}$, experimental error. Leaf size score scale: 1 , very small to 5 , very large. 
significant genotype-by-year and genotype-by-season interactions for dry matter yield among white clover breeding lines evaluated for 3 years under rotational sheep grazing.

The biplot (Figure 2) presents a graphical summary of performance, based on mean seasonal growth, of the 16 white clover cultivars across the three locations, as indicated by the directional vectors. These vectors showed a positive association among the three locations (angles between the directional vectors are at $<90^{\circ}$ ). However, the cattle grazed locations, PN and Ker, were strongly correlated. Cultivar groups 1 and 2 , generated from cluster analysis of seasonal growth of the 16 cultivars at Ker, PN and Lin, showed above average seasonal growth at the cattle and sheep grazed locations, respectively. The $c v$ Legacy showed broad adaptation across both cattle and sheep grazing, and $c v$ Hilltop showed good above average seasonal growth under sheep grazing across the 4 years. There was a clear indication that the large leaf cultivars performed best under cattle grazing. Similar observations have been made by Brock and Hay (1996). The small to medium leaf cultivars Hilltop, Bounty and Tribute had

Table 2 Estimated variance components ${ }^{\dagger}$ and associated standard error $( \pm \mathrm{SE})$ for seasonal growth evaluated at Kerikeri, Palmerston North and Lincoln, among the 60 white clover entries 44 experimental synthetics and 16 commercial cultivars), from Residual Maximum Likelihood analysis.

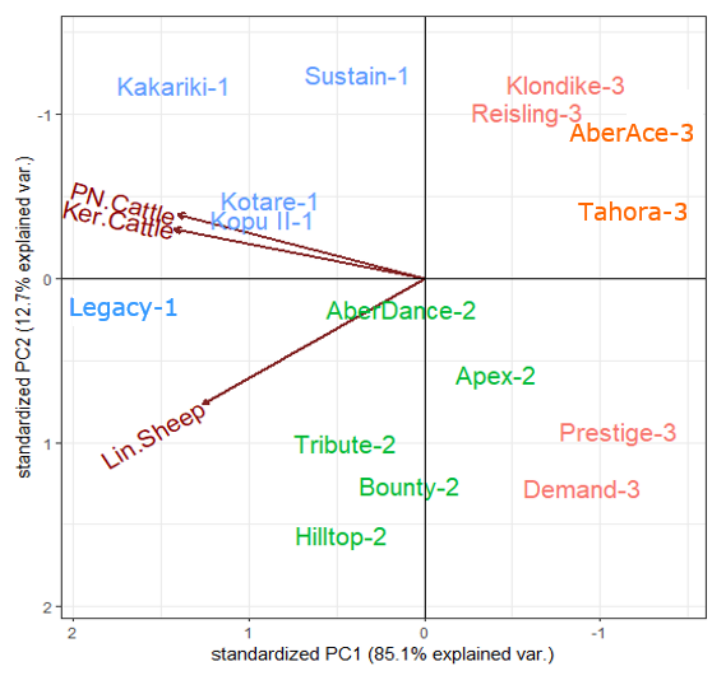

Figure 2 Biplot generated from pattern analysis of standardized best linear unbiased predictor values of the 16 white clover commercial cultivars based on within individual location (Ker, Kerikeri; PN, Palmerston North; Lin, Lincoln) analysis of growth across seasons and 4 years under rotational grazing. The number following each cultivar indicates the group generated from cluster analysis. Each directional vector represents a location, and the grazing type cattle or sheep is indicated.

\begin{tabular}{|c|c|c|c|c|c|}
\hline Traits & $\sigma_{g}^{2}$ & $\sigma_{g y}^{2}$ & $\sigma_{g s}^{2}$ & $\sigma_{g l}^{2}$ & $\sigma_{\varepsilon}^{2}$ \\
\hline $\begin{array}{l}\text { Mean seasonal growth } \\
\text { across } 4 \text { years at Palmerston North }\end{array}$ & $1.275 \pm 0.263$ & $0.273 \pm 0.041$ & $0.088 \pm 0.020$ & - & $1.456 \pm 0.034$ \\
\hline $\begin{array}{l}\text { Mean seasonal growth } \\
\text { across } 4 \text { years at Lincoln }\end{array}$ & $0.502 \pm 0.114$ & $0.408 \pm 0.056$ & $0.031 \pm 0.016$ & - & $1.500 \pm 0.041$ \\
\hline $\begin{array}{l}\text { Mean seasonal growth } \\
\text { across } 4 \text { years at Kerikeri }\end{array}$ & $0.283 \pm 0.071$ & $0.182 \pm 0.040$ & $\mathrm{~ns}^{*}$ & - & $1.543 \pm 0.053$ \\
\hline $\begin{array}{l}\text { Mean spring growth } \\
\text { across } 4 \text { years and } 3 \text { locations }\end{array}$ & $0.341 \pm 0.102$ & $0.073 \pm 0.024$ & ns & $0.385 \pm 0.066$ & $1.683 \pm 0.047$ \\
\hline $\begin{array}{l}\text { Mean summer growth } \\
\text { across } 4 \text { years and } 3 \text { locations }\end{array}$ & $0.176 \pm 0.078$ & $0.122 \pm 0.031$ & - & $0.441 \pm 0.073$ & $1.606 \pm 0.044$ \\
\hline $\begin{array}{l}\text { Mean autumn growth } \\
\text { across } 4 \text { years and } 3 \text { locations }\end{array}$ & $0.292 \pm 0.116$ & Ns & - & $0.653 \pm 0.112$ & $1.444 \pm 0.067$ \\
\hline $\begin{array}{l}\text { Mean winter growth } \\
\text { across } 4 \text { years and } 3 \text { locations }\end{array}$ & $0.543 \pm 0.157$ & $0.140 \pm 0.039$ & - & $0.532 \pm 0.090$ & $1.607 \pm 0.054$ \\
\hline $\begin{array}{l}\text { Mean growth across all seasons, } \\
4 \text { years and } 3 \text { locations }\end{array}$ & $0.291 \pm 0.094$ & $0.110 \pm 0.018$ & $0.026 \pm 0.008$ & $0.451 \pm 0.064$ & $1.622 \pm 0.025$ \\
\hline
\end{tabular}

* non-significant $(P>0.05)$,

† a variance component is considered significant $(\mathrm{P}<0.05)$ if it is 1.96 (form two-tailed test) times greater than its standard error. Only significant $(\mathrm{P}<0.05)$ variance components are reported. Variance components: $\sigma_{g}^{2}$, genotypic; $\sigma^{2}$ gy genotype-by-year interaction; $\sigma_{g s}^{2}$, genotype-by-season interaction; $\sigma_{g l}^{2}$ genotype-by-location interaction; $\sigma_{\varepsilon}^{2}$, experimental error. Growth score scale: 1 poor to 9 high. 
above average growth under rotational sheep grazing (Figure 2).

It is important to note that the within-seasonal growth means across locations and years were based on data generated from the two cattle grazed trials at Ker and $\mathrm{PN}$, and the sheep grazed trial at Lin. The directional vectors in Figure 3 indicated a positive correlation (angles between the directional vectors are at $<90^{\circ}$ ) among the four seasons. All cultivars in group 3, Hilltop, Tribute, Legacy and Kakariki, had high above average growth in all seasons. All cultivars in group 2 had above average performance across all seasons, except for AberDance which only showed high above average performance in spring, winter and summer.

\section{Analysis of within individual year seasonal growth under sheep grazing}

There was significant $(\mathrm{P}<0.05)$ genotypic variation for mean seasonal growth among the 60 white clover entries within each year of the 6-year trial at Lincoln (Table 3). The magnitude of genotypic variation among the entries decreased under rotational grazing over the 4-year period. However, under set stocking in year 5 of the field trial, genotypic variation increased, but then decreased significantly in year 6 .

Principle component analysis of the 16 white clover cultivar-by-mean annual seasonal growth score matrix indicated a change in annual performance across the years (Figure 4). A strong positive correlation (where angles between the directional vectors were at $<90^{\circ}$ ) between year 1 and year 2 under rotational grazing changed to a moderate negative correlation (where angles between the directional vectors became $>90^{\circ}$ ) between years 1 and 4 . This indicated that the relative performance among the cultivars changed across the 4 years of rotational grazing.

During the first 12 to 18 months of growth, the white clover plant loses its primary seedling taproot and then

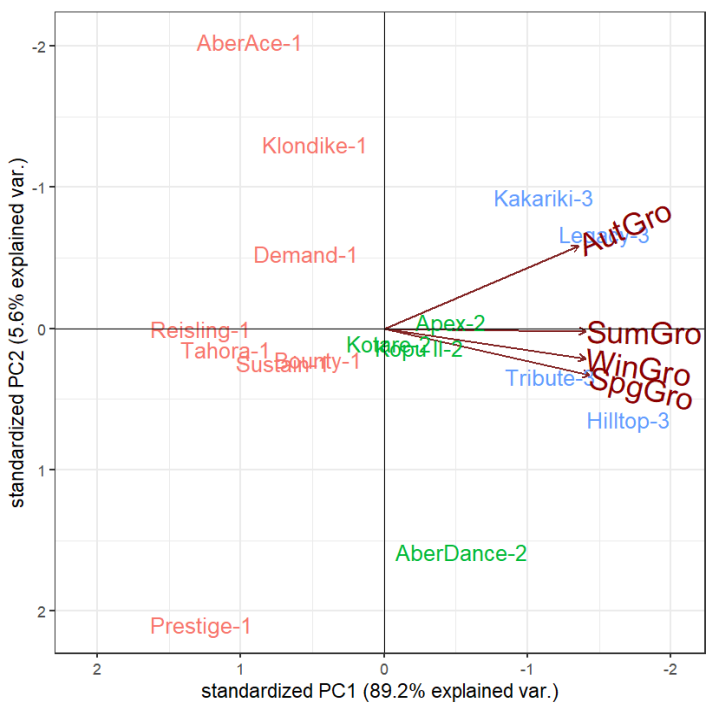

Figure 3 Biplot generated from pattern analysis of standardized best linear unbiased predictor values of the 16 white clover commercial cultivars based on within seasonal growth (AutGro, autumn; SumGro, summer; WinGro, winter; SpgGro, spring) analysis across 4 years and three locations (Kerikeri, Palmerston North, Lincoln) under rotational grazing. The number following each cultivar indicates the group generated from cluster analysis. Each directional vector represents a season.

depends on nodal roots for ongoing nutrient and water uptake (Westbrooks and Tesar 1955; Caradus 1990). These morphological and physiological changes, together with plant growth phases such as annual stolon fragmentation during early spring (Hay et al., 1983) and coupled with animal grazing effects contributed to complex genotype-by-environment interactions which may have contributed to the significant changes seen in cultivar performance across years.

Table 3 Estimated variance components ${ }^{\dagger}$ and associated standard error $( \pm$ SE) form Residual Maximum Likelihood analysis of within individual year seasonal growth, among the 60 white clover entries (44 experimental synthetics and 16 commercial cultivars), evaluated at Lincoln under sheep grazing (years 1 to 4 using rotational grazing and years 5 to 6 using set stocking).

\begin{tabular}{lccc}
\hline Trait & $\boldsymbol{\sigma}^{2}{ }_{\mathbf{g}}$ & $\boldsymbol{\sigma}^{2}{ }_{\mathbf{g s}}$ & $\boldsymbol{\sigma}_{\boldsymbol{\varepsilon}}{ }^{2}$ \\
\hline Year 1 rotational grazing & $1.711 \pm 0.310$ & $\mathrm{~ns}{ }^{*}$ & $1.161 \pm 0.054$ \\
Year 2 rotational grazing & $1.070 \pm 0.214$ & $\mathrm{~ns}$ & $1.800 \pm 0.105$ \\
Year 3 rotational grazing & $0.601 \pm 0.170$ & $\mathrm{~ns}$ & $1.810 \pm 0.167$ \\
Year 4 rotational grazing & $0.575 \pm 0.129$ & $\mathrm{~ns}$ & $0.974 \pm 0.067$ \\
Year 5 set stocking & $0.910 \pm 0.151$ & $\mathrm{~ns}$ & $1.256 \pm 0.068$ \\
Year 6 set stocking & $0.455 \pm 0.148$ & $\mathrm{~ns}$ & $1.700 \pm 0.155$ \\
\hline
\end{tabular}

* non-significant $(\mathrm{P}>0.05),{ }^{\dagger}$ a variance component is considered significant $(\mathrm{P}<0.05)$ if it is 1.96 (form two-tailed test) times greater than its standard error. Variance components: $\sigma_{g}^{2}$, genotypic; $\sigma_{g s}^{2}$, genotype-by-season interaction; $\sigma_{\varepsilon}^{2}$, experimental error. Growth score scale: 1 , poor to 9 , high. 


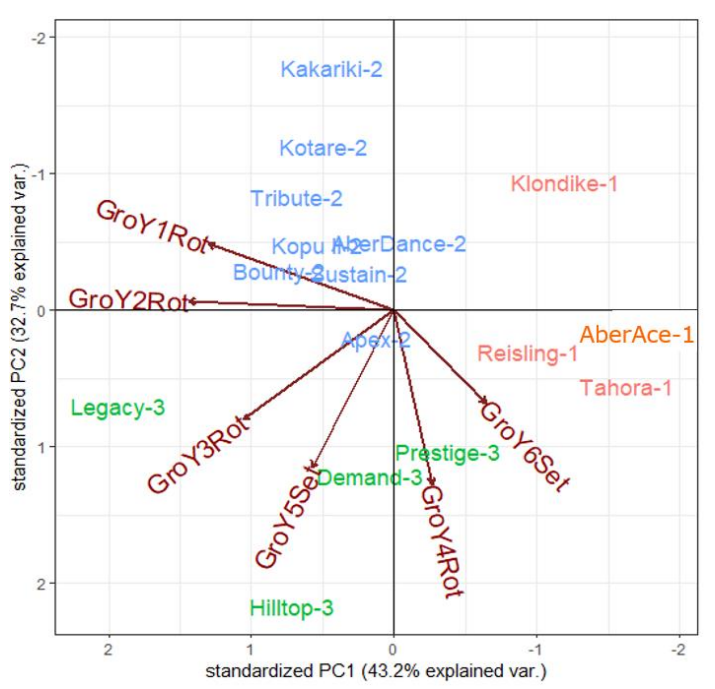

Figure 4 Biplot generated from pattern analysis of standardized best linear unbiased predictor values of the 16 white clover commercial cultivars based on within individual year mean seasonal growth scores measured at Lincoln, under sheep grazing. The number following each cultivar indicates a cultivar group generated from cluster analysis. Each directional vector represents mean seasonal growth (Gro) of a particular year (Y.) under rotational (Rot) or set stocking (Set).

Cultivar responses to set stocking in year 5 of the Lin trial indicated a change in mean seasonal yield response of the cultivars, with a stronger positive correlation in year 5 to year 3 rotational grazing. The performance of cultivars in year 6 under set stocking was strongly negatively correlated to year 1 rotational grazing. The members of group 2 generated from cluster analysis consisted mainly of very large to medium leaf cultivars which had above average performance in years 1 and 2 under rotational sheep grazing. All cultivars in group 2, except Apex, showed below average performance in year 4. Apex had an average performance across all years. Group 3 consisted of cultivars Demand (SM), Hilltop (S), Legacy (L) and Prestige (S). Legacy showed above average performance across all years of rotational sheep grazing and in the first year of set stocking. The $c v$ Legacy had below average performance in year 6 . The performance of $c v$ Hilltop was slightly below average in year 1 of the trial, although its performance improved over time, from above average in year 2 under rotational grazing to above average in years $3,4,5$ and 6 . The $c v$ Hilltop showed above average performance under sheep grazing. The $c v$ Demand and Prestige had above average performance in years 4, 5 and 6 .

The significant genotype-by-environment interactions estimated for both traits seasonal growth and leaf size emphasized the importance of conducting multi-location-year-season trials for evaluating breeding and commercial plants. The importance of conducting evaluation trials under both cattle and sheep grazing with different grazing management methods (rotational/set stocking) was demonstrated. The close association between the results from Ker and PN (Figure 2) suggested that there may be an opportunity to develop more discriminating combinations of grazing management and location.

In terms of specific cultivar performance relevant to the objective of broad adaptability, $c v$ Legacy showed above average performance across all three locations. The $c v$ Hilltop showed above average seasonal growth across all years under the rotational sheep grazing management at Lin. These results agreed with those reported by Brock and Hay (1996) that indicated superior performance of large leaved and small leaved white clover under rotational and set stocking, respectively. In the current study, $c v$ Hilltop showed above average seasonal growth under set socking with sheep in years 5 and 6 at Lin.

Hilltop is a new breed of white clover in the small to medium leaf range of cultivars recommended for rotational and set stock grazing management. It was bred using superior lines developed from diverse germplasm screened in browntop (Agrostis capillaris) pasture under rotational grazing by sheep. Final selection of the experimental synthetic line, coded as 'Competition browntop' now named Hilltop, was based on results from multi-location and year evaluation trials across New Zealand. This demonstrated the value of evaluating breeding plants across locations and different management systems to develop broadly adapted cultivars for the New Zealand farmer.

The plasticity of modern cultivars is important for adaptation to environmental variation due to factors such as soil fertility, spatial and temporal climatic variation and different grazing management systems. The effect of applying different levels of phosphorus $(\mathrm{P})$ on white clover phenotypic plasticity of morphological and yield related traits has been reported by Caradus et al., (1993).

Hilltop is a good example of a cultivar that can perform over years and seasons in multiple environments and grazing managements. This cultivar provides farmers with a new option to further enhance forage production in sheep and beef pastoral systems.

\section{ACKNOWLEDGEMENTS}

The authors wish to acknowledge Phil Olyott and Kathyrn Pankhurst at Northland, Doug Ryan at Waikato, Keith Widdup and Ben Harvey at Lincoln. They would like to thank the farm staff in NorthlandKeriKeri, Aorangi- Manawatu and AgResearch Lincoln - Canterbury, for their assistance in conducting the field trials successfully. 


\section{REFERENCES}

Abberton MT, Marshall AH. 2010. White Clover, in: B. Boller, et al., (Eds.), Fodder Crops and Amenity Grasses, Springer New York. pp. 457-476. https:// doi.org/10.1007/978-1-4419-0760-8_19

Brock JL, Hay MJM. 1996. A review of the role of grazing management on the Growth and performance of white clover cultivars in lowland New Zealand pastures. White clover: New Zealand's Competitive Edge. Agronomy Society of New Zealand Special Publication No.11: Grasslands Research and Practice Series 6: 65- 70. https://doi.org/10.33584/ rps.6.1995.3379

Brock JL, Caradus JR, Hay MJM. 1989. 50 years of white clover research in New Zealand. Proceedings of the New Zealand Grassland Association 50: 2539. https://doi.org/10.33584/jnzg.1989.50.1868

Caradus JR. 1994. Genetic diversity in white clover. Proceedings of the New Zealand Grassland Association 24: 1-7. https://www.researchgate. net/profile/John-Caradus/publication/280105384_ Genetic_diversity_within_white_clover_Trifolium_ repens_L/links/55a9f16508ae481aa 7f99071/ Genetic-diversity-within-white-clover-Trifoliumrepens-L.pdf

Caradus JR. 1993. White clover breeding line performance under sheep and cattle grazing. Proc. Tenth Aust. Plant Breeding Conf., Gold Coast, Vol. II, pp. 35-36.

Caradus, JR. 1991. Evaluation of elite white clover germplasm under rotational cattle and sheep grazing. Proceedings of New Zealand Grasslands Association 53: 105-110. https://doi.org/10.33584/ jnzg.1991.53.1989

Caradus, JR. 1990. The structure and function of white clover root systems. Advances in Agronomy 43: 1-46. https://doi.org/10.1016/S0065-2113(08)60475-7

Caradus JR, Hay MJM, Mackay AD, Thomas VJ, Dunlop J, Lambert MG, Hart AL, van den Bosch J, Wewala S. 1993. Variation within white clover (Trifolium repens L.) for phenotypic plasticity, of morphological and yield related characters, induced by phosphorus supply. New Phytologist 123: 175184. https://doi.org/10.1111/j.1469-8137.1993. tb04543.xCitations: 21

Cooper M, Byth DE. 1996. Understanding plant adaptation to achieve systematic applied crop improve- ment - A fundamental challenge. In 'Plant Adaptation and Crop Improvement'. (Eds M. Cooper, and G. L. Hammer). pp. 5-23. (CAB International, Wallingford, UK). https://books.google.co.nz/books?id=3mSRCLrbqkQCandlpg=PA5 andots $=$ b8hddziIZaand $\mathrm{dq}=$ cooper 1996 understanding plantandlrandp$\mathrm{g}=$ PR3 - $\mathrm{v}=$ onepageandq $=$ cooper 1996 understanding plantandf $=$ false

Ewing PM, Runck BC, Kono TYJ, Kantar MB. 2019. The home field advantage of Modern plant breeding. PLoS ONE 14(12): https://doi.org/10.1371/journal. pone.0227079

Ford JL, Cousins GR, Jahufer Z, Baird IJ, Woodfield DR, Barrett BA. 2015. Grasslands Legacy - a new, large-leaved white clover cultivar with broad adaption. Journal of New Zealand Grasslands 77: 211-218. https://doi.org/10.33584/jnzg.2015.77.458

Frame J, Newbould P. 1986. Agronomy of white clover. Advances in Agronomy 40: 1-88. https://doi. org/10.1016/S0065-2113(08)60280-1

Hay RJM, Lancashire JA. 1995. Cultivar development and links to industry. Proceedings of a joint symposium between Agronomy Society of New Zealand and New Zealand Grassland Association 6: 15-18. https://doi. org/10.33584/rps.6.1995.3369

Hay MJM, Brock JL, Fletcher RH. 1983. Effect of sheep grazing management on distribution of white clover stolons among 3 horizontal strata in ryegrass/white clover swards. New Zealand Journal of Experimental Agriculture 11: 215-218. https://doi.org/10.1080/0301 5521.1983 .10427757

Jahufer MZZ, Ford JL, Woodfield DRW, Barrett BA. 2016. Genotypic evaluation of introduced white clover (Trifolium repens L.) germplasm in New Zealand, Crop and Pasture Science: 67, 897-906. https://doi.org/10.1071/CP16149

Jahufer MZZ, Cooper M, Ayres JF, Bray RA. 2002. Identification of future research to improve the efficiency of conventional white clover breeding strategies in Australia - A review. Australian Journal of Agricultural Research, 53, 239-256. https://doi. org/10.1071/AR01110

Westbrooks FE, Tesar MB. 1955. Tap root survival of ladino clover. Agronomy Journal. 47: 403-10. https:// doi.org/10.2134/agronj1955.000219620047000900 $04 x$ 